\title{
Medición de genotoxicidad cromosomática de meristemos de Eucaplytus glóbulus labill inducidas por cafeína y carbetamida
}

\author{
Félix PALACIOS MORALES'
}

\begin{abstract}
RESUMEN
Objetivo: Describir la genotoxicidad cromosómica en meristemos de Eucalyptus glóbulus Labill inducidos por cafeína y carbetamida de las aberraciones causadas en cada fase mitótica Metodología: Las semillas fuerón sembradas en placas Petri estériles, y se colocaron 20 semillas por siete días de germinación. Las raíces alcanzaron una longitud de uno a dos centímetros desinfectadas en solución de cloro - agua destilada (3:1). Después de la germinación se aplicaron los tratamientos cuatro horas en cafeína y doce de recuperación, en el caso de la carbetamida una hora de tratamiento sin tiempo de recuperación. Resultados: Se determinó el proceso mitótico en células radicales de Eucaliptus globulus susceptibles a cafeína y carbetamida. La investigación se llevó a cabo en las raicillas seleccionadas de las plántulas con mejor vigor y crecimiento en placas petri de $20 \mathrm{~cm}$. de diámetro en el laboratorio de Biología. Se empleó la técnica del aplastamiento y tinción con acetorceína clorhídrica para el análisis mitótico, estudiando un promedio de 1051.5 células/planta. Tomando $0.2 \mathrm{~mm}$. de la región meristemática. Los cortes de la raíz se realizaron cada hora por 24 horas. La mayor cantidad de células mitóticas se observaron en raíces colectadas entre 6:00 - 9:00 am donde se registraron los mayores índices mitóticos (IM), de 87.34\% y 79.71\%). Para las diferentes estadíos de fase mitótica el estudio indicó que la profase se presentó en mayor proporción ( $87.34 \%$ y $69.71 \%)$, seguida de la metafase $(4.08 \%$ y $4.98 \%)$, anafase $(3.67 \%$ y $8.54 \%$ ) y telofase $(4.89 \%$ y $6.76 \%)$ respectivamente de los tratamientos entre células con cafeína y carbetamida. Conclusiones: El estudio de los estadios mitóticos, indicó el índice profásico aberrante en escala dos, similar proporción presentó la carbetamida seguida por metafase, anafase y telofase, indicando sensibilidad celular a la acción química del medicamento en el período proliferativo meristemático que inhibe la división generando células binucleadas y polinucleadas.
\end{abstract}

Palabras clave: Células radiculares, células mitóticas, ciclo celular, cafeína, carbetamida.

\begin{abstract}
Objective: Describe the chromosomal genotoxicity Eucalyptus globulus Labill meristems induced by caffeine and the aberrations caused carbetamida in each mitotic phase. Methodology: Seeds sown in sterile Petri dishes with 20 seeds per seven days of germination, the roots reach a length of one to two centimeters disinfected in bleach solution - distilled water (3:1). After germination treatments applied caffeine four hours and twelve of recovery, in the case of one hour of treatment carbetamida no downtime. Results: We determined the mitotic process of Eucalyptus globulus radical cells susceptible to caffeine and carbetamida. The research was carried out in selected rootlets of seedlings with more vigor and growth in petri dishes $20 \mathrm{~cm}$ in diameter in the biology lab. The technique of crushing and staining with hydrochloric acetorceína mitotic analysis, studying an average of 1051.5 cells / plant. Taking 0.2 $\mathrm{mm}$ from the growth region. The root cuttings were made every hour for 24 hours. Most mitotic cells were observed in roots collected between 6:00 to 9:00 a.m. which recorded the highest mitotic index (MI) of 87.34\% and 79.71\%). For the different stages of mitotic phase The study indicated that the prophase were in higher proportion $(87.34 \%$ and $69.71 \%)$, followed by metaphase $(4.08 \%$ and $4.98 \%)$, anaphase $(3.67 \%$ and $8.54 \%)$ and telophase $(4.89 \%$ and $6.76 \%$, respectively) between treatments with caffeine and carbetamida cells.Conclusion: The study of mitotic stages, said the index scale aberrant profásico two similar proportion carbetamida presented followed by metaphase, anaphase and telophase, indicates cellular sensitivity to the chemical action of the drug in the period that inhibits proliferative meristematic cell division generates binucleated and multinucleated.
\end{abstract}

Keywords: Root cells, mitotic cells, cell cycle, caffeine, carbetamida.

${ }^{1}$ Jefe de Laboratorio de Biología, Docente de la E.A.P de Nutrición Humana, Universidad Peruana Unión. 


\section{INTRODUCCIÓN}

La influencia de genotoxicidad medio-ambiental en Eucalytus globulus Labill inducidas durante cuatro horas en cafeína a $0.025 \%$ más 12 horas de recuperación. A $25^{\circ} \mathrm{C}$ y carbetamida en una solución al $0.007 \%$ durante cuatro horas a $25^{\circ} \mathrm{C}$, el tratamiento fue aplicado a plántulas germinadas y observadas en células meristemáticas coloreadas con orceína acética y utilizado al técnica del "Squash", fundamentada en el período proliferativo del ciclo celular tomando como indicador interfásico, G1, S y G2 y observado a nivel de cromosomas en el período Mitótico (M); luego se utilizó el microscopio seguido del microfotografiado para evaluar las células proliferativas aberradas.

Las variaciones del balance hormonal o al agregar sustancias inductoras al medio del cultivo causan alteraciones al aparato cromosómico pueden ser evaluadas por métodos de análisis citogenéticas cuantitativos o cualitativos que registran las variaciones del aparato cromosómico por influencia química intra y extracelular de diferentes factores durante el período. El número de semillas utilizadas es de 20 unidades por placa, soportadas en papel filtro con un período de germinación de seis días con intercambio diario de agua, del mismo modo se encontró un índice mitótico (IM) de $(87.34 \%$ y $79.71 \%)$.

El estudio indicó que la profase se presentó en mayor proporción $(87.34 \%$ y $69.71 \%$ ), seguida de la metafase (4.08\% y $4.98 \%)$, anafase $(3.67 \%$ y $8.54 \%)$ y telofase (4.89\% y $6.76 \%$ ) respectivamente, de los tratamientos entre células con cafeína y carbetamida con cromátides aberradas y fragmentos cromatídicos múltiples; por corte de una cromátide también se han observado translocación cromática en el líquido intracelular al formarse células binucleadas por efecto de la cafeína al inhibir la formación del surco de división, las placas se introducen al termostato a $25^{\circ} \mathrm{C}$ en cámara húmeda a diferentes tiempos de tratamiento, evaluándose las células aberrantes con la fórmula correspondiente. En el presente trabajo se tuvo como objetivo: Describir la genotoxicidad cromosómica en meristemos de Eucalyptus glóbulus Labill inducidos por cafeína y carbetamida de las aberraciones causadas en cada fase mitótica.

\section{MATERIAL Y MÉTODOS}

Las semillas de eucalipto seleccionados proceden del huerto semillero del campo experimental de la UNCP - Huancayo. Esta zona se caracteriza por presentar una precipitación media anual entre 760 y $850 \mathrm{~mm}$, temperatura promedio entre $18^{\circ}$ y $8^{\circ} \mathrm{C}$, suelos limitados con textura gruesa, fertilidad natural de moderada a baja, con un horizonte argílico a diferentes profundidades, de textura franco arenoso, baja capacidad de retención de humedad y un PH entre 6 y 7.

Se recolectaron las semillas de seis frutos por cada árbol seleccionadas con tamaño uniforme, forma regular y descartando las amorfas, estériles y sembradas en placas Petri previamente esterilizadas, fueron colocadas 20 semillas por placa a una temperatura de 25 a $30^{\circ} \mathrm{C}$ por un período de seis a siete días de germinación, las raíces alcanzan una longitud de uno a dos centímetros desinfectadas en solución de cloro comercial con agua destilada (agua-cloro comercial 3:1), luego se procede a preparar "el Kit" de soluciones de cafeína al 0.025\% y carbetamida al $0.007 \%$, después del período de germinación se aplican los tratamiento por cuatro horas en cafeína y doce horas de recuperación, en el caso de la carbetamida, una hora de tratamiento sin tiempo de recuperación, luego las raíces son extraídas y colocadas en un vidrio de reloj conteniendo orceína acétoclorhídrica al $2 \%$ calentando y enfriando a la llama del mechero por tres veces para provocar la tinción cromosómica monocrómatica en forma independiente por cada tratamiento (Alam, Kabir, Amin \& Islam, 1987).

Se empleó el método de aplastamiento o "squash" de los $2 \mathrm{~mm}$ de meristemos para la preparación de las láminas microscópicas, de acuerdo la técnica propuesta por Matos y Molina (1997) con algunas modificaciones.

La observación de células se llevó a cabo en un fotomicroscopio marca Karl Zeiss y se cuantificó el número de células en interfase y mitóticas por campo microscópico en objetivo de 40X en cada fase de la mitosis del ciclo celular encontrándose células mitóticas proliferantes en división cuyos cromosomas presentan deleciones y fragmentaciones en sus brazos cromatídicos los que fueron microfotografiados para su interpretación a nivel genotóxico.

Los cálculos del Índice Mitótico (IM) y de los Índices de Fases (IF) se llevaron a cabo usando las ecuaciones utilizadas por Del Campo (1988), donde el IM se obtiene mediante la ecuación: $\mathrm{IM}=\mathrm{N}^{\mathrm{o}}$ de núcleos en mitosis/ Total de núcleos observados $\times 100$ y el IF se obtuvo utilizando la ecuación: IF $=\mathrm{N}^{\mathrm{o}}$ de célula en fase/ Total de células en mitosis $\times 100$.

Tamaño de la muestra.

Se han utilizado 20 semillas seleccionadas de eucalipto por placa petri de un lote de $100 \mathrm{gr}$.

\section{Factores de estudio}

Se considera el índice mitótico aberrante y los índices de las diferentes fases de la mitosis proliferante de los meristemos en estudio.

Índice mitótico aberrante (IMa) 
Índice profásico aberrante (IPa)

Índice metafísico aberrante (IMa)

Índice anafàsico aberrante (IAa)

Índice telofásico aberrante (ITa)

\section{Características}

Número de semillas por placa $: 20$

Número de placas petri $\quad: 6$

Número de raíces por planta : 1

\section{Evaluaciones}

Después de los siete días de hace el preparado en forma individual por cada tratamiento y del proceso de observación se tomaron los datos siguientes:
- Número de células aberradas para determinar el IM aberrado.

- Número de células aberradas en mitosis para el índice de fases.

- Número de células por punta de raíz en cinco campos visuales.

- Las evaluaciones se realizaron en forma secuencial con intervalos de cuatro horas, de tratamiento y doce horas de recuperación, detectándose las fases mitóticas de acuerdo al estado de los cromosomas y la súper fragmentación de los brazos de los cromosomas o una porción de ellas, para establecer algunas comparaciones de utilidad respeto al efecto del tratamiento químico aplicado.

\section{RESULTADOS}

Tabla 1

Número de células proliferantes

NÚMERO DE OBSERVACIONES X CAMPO

25

25

\section{NÚMERO DE CÉLULAS INTERFÁSICAS PROLIFERANTES.}

980

1123

Tabla 2

Número de células proliferantes mitóticas aberrantes

\begin{tabular}{lcccccc}
\hline MEDICAMENTO & I & P & M & A & T & TOTAL \\
\hline Cafeína & 735 & 214 & 10 & 9 & 12 & 980 \\
Carbetamina & 842 & 224 & 14 & 24 & 19 & 1123 \\
\hline
\end{tabular}

Tabla 3

Porcentaje de daño a las cromátides mitóticas de células tratadas con cafeína y carbetamida

\begin{tabular}{lccccc}
\hline TRATAMIENTO & $\mathrm{IMa} \%$ & $\mathrm{IPa} \%$ & $\mathrm{IMa} \%$ & $\mathrm{IAa} \%$ & $\mathrm{ITa} \%$ \\
\hline CAFEÍNA & 25.00 & 87.34 & 4.08 & 3.67 & 4.89 \\
CARBETAMIDA & 33.37 & 79.71 & 4.98 & 8.54 & 6.76 \\
\hline
\end{tabular}

Tabla 4

Efecto químico en las cromátides niveles

\begin{tabular}{lcc}
\hline NIVEL & CAFEÍNA $0.0025 \%$ & CARBETAMIDA $0.007 \%$ \\
\hline BAJO & 0 & 0 \\
\hline MEDIO & 1 & 1 \\
\hline ALTO & 2 & 2 \\
\hline
\end{tabular}


La investigación ha mostrado que en los tratamientos cuyo efecto a nivel de cromátides y cromosómicas durante el período proliferátivo del ciclo celular predominan las células dañadas en profase y anafase, algunas inhiben la condensación profase y anafase y la condensación de la cromátida, al margen que hay un buen porcentaje de interfase. Al aplicar cafeína al $0.025 \%$ las células meristemáticas por un tiempo de cuatro horas de tratamiento y doce horas de recuperación se encontró que un 95\% de células en interfase cuyo indicador es la del nucleolo no sintetizado, después de la recuperación se formó un $25 \%$ de células mitóticas y un $75 \%$ de profases iniciales.

El núcleo está alargado en extremo donde la sustancia provoca la flacidez membranal de la pared celular por la acción química del medicamento, la características del efecto es que presenta dos cromosomas normales una cromátide polifragmentada con los extremos escindidos y el otro componente contiene al centrómero, el brazo libre divaga en el citoplasma sin orientación, además inhiben la formación del uso acromático impidiendo la maduración celular.

Asimismo, la carbetamida presenta células en un $45 \%$ en profase y un $65 \%$ de metafase, anafase y telofase; éste actúa como indicador inductor de la población en el flujo celular poliferante en los meristemos de eucalipto. En éste tejido en 1.1 sección lateral de las yuxtaposiciones celulares las células están desprendidas en formas de hilachas, de un color café claro, el efecto inhibe la replicación modificando al actividad cromosomal potentemente por su amplio espectro de fragmentación cromosómica aberrante a nivel estructural que causan deleciones, donde la células realizan sus rearreglos estructurales después de un tiempo de recuperación y alcanza una performance sin repercusión fenotipica (desbalancedas) ocasionando una patología deletérea, estas sustancias ocasionan en común malformaciones y deficiencias en la fisiología durante el ciclo celular, dichas características determinaron una repercusión en el vehículo de la información hereditaria.

Asimismo, los niveles de daños ocasionados son 0,1 y 2 indicados como bajo, medio y alto siendo que la carbetamida tuvo un nivel alto de efecto en los cromosomas lo mismo que el porcentaje aberrante mitótico alcanza para la cafeína un $52.80 \%$ y para el caso de la carbetamida de un $47.16 \%$, habiéndose encontrado la mayor cantidad de células aberrantes con 224 células y para el caso de la cafeína encontraron 214 células.

\section{CONCLUSIONES}

- La hora de mayor proliferación mitótica en los tratamientos de carbetamida y cafeína osciló entre las de 6:00 y 9:00 am bajo las condiciones de manejo en el laboratorio donde se registraron los mayores índices de células aberradas en las distintas fases del ciclo.
- El estudio de las frecuencias de los estadios mitóticos, indicó que el índice profásico aberrante en la escala 2, de similar proporción presentó la carbetamida seguida de la metafase, anafase y telofase. Esto indica la sensibilidad celular a la acción química del medicamento utilizado en el período proliferativo de células meristemáticas inhibición de las que generan células bi y polinucleadas.

\section{REFERENCIAS BIBLIOGRÁFICAS}

1. Abeefe, M. S.,(2003), Panorama médico, publicación Nro. 14:24.

2. Alam, G. kabir, N. Amin y M. Islam. (1987) Mitotic effect of leaf extracts of.

3. Del Campo A. (1988) Biología del ciclo de división celular. Ediciones Astro Data S.A. Maracaibo, Venezuela. 55 .

4. Gouy. M \& Goutier, C. (2003) Correlation whit Escisión of genome, Biol.; , 33:73547.

5. Guizar. V. J. (1999). Genética clínica. Ed EMM, S.A. de C.V. México D.F. 546 p. Ipomoea carnea on Allium cepa. Cytologia; 52: 721-724.

6. Matos A., J. Molina, D. Acosta y M. Abreu. (1995). Determinación del proceso mitótico en células radicales de Prosopis judiflora DC. Ciencia; 3 (2):83-90.

7. R.W. Old y S.B. Primrose. (2006). Principios de manipulación genética. Editorial Acribia S.A.

8. Robertis y de Robetis. (2004). Biología Celular y molecular, Editorial el Ateneo. Buenos Aires.

9. U.N.C.P. (2003) Resúmenes de trabajos de investigación, Ed. TOPIUNCP; 163. 